\title{
Frequency of Metabolic Abnormalities in Pakistani Children With Renal Stones
}

\author{
Muhammad Tanveer Sajid, ${ }^{\otimes 1}$ Muhammad Rafiq Zafar, ${ }^{1}$ Qurat-UI-Ain Mustafa, ${ }^{2}$ Rabia Abbas, ${ }^{3}$ \\ Sohail Raziq, ${ }^{1}$ Khurram Mansoor ${ }^{1}$ \\ ${ }^{1}$ Armed Forces Institute of Urology, Rawalpindi, Pakistan ${ }^{2}$ Army Medical College, Rawalpindi, Pakistan ${ }^{3}$ Pak Emirates Military Hospital, Rawalpindi, Pakistan
}

\section{Abstract}

Objective To determine the frequency of various metabolic abnormalities in children with urinary lithiasis.

Methods This cross-sectional study was conducted at the Armed Forces Institute of Urology, Rawalpindi, from 30 January 2017 to 1 February 2020. A total of 1355 children who were aged 4 to 14 years and who had renal stones were included, while those with urinary tract infections, posterior urethral valve, pelvi-ureteric junction obstruction, reflux disease, and chronic renal failure were excluded. Twenty-four-hour urine samples were analyzed for urinary uric acid, calcium, oxalate, citrate, and magnesium. Demographics and metabolic abnormalities-hypercalciuria, hyperoxaluria, hypocitraturia, hyperuricosuria, and hypomagnesuria-were noted and analyzed.

Results The study analysis included 1355 patients. Low urine volume was observed in 465 (34.3\%) of the patients. Three hundred nine patients $(22.8 \%)$ had metabolic abnormalities, the most common being hypocitraturia (184, $59.5 \%)$ followed by hypercalciuria $(136,44 \%)$ and hypomagnesuria $(126,40.8 \%)$. Mean age of presentation, disease duration, recurrent bilateral stones were found significantly different in those having metabolic abnormalities (7.81 \pm 2.25 versus $8.76 \pm 2.50 P<0.001,7.73 \pm 1.50$ versus $8.43 \pm 1.54 P<0.001,19.4$ versus $2.4 \% P<0.001$ respectively). No significant difference was found in frequency of abnormal urinary metabolic parameters between boys and girls $(P>0.05)$ or, upon data stratification, on the basis of disease duration, stone laterality, and recurrence.

Conclusions Metabolic abnormalities were found in $22.8 \% \%$ of children presenting with urinary lithiasis. The most frequent abnormality observed was hypocitraturia followed by hypercalciuria and hypomagnesuria. Early identification helps manage such patients appropriately, mitigating long-term sequelae.

\section{Introduction}

There has been a sharp rise in urinary lithiasis in the pediatric population over the past couple of decades, probably due to global warming and the widespread westernization of diet, which has led to the obesity pandemic, as well as other environmental factors[1]. Although the true incidence is not known, it is estimated that $6 \%$ to $10 \%$ of children are affected. Although the lifetime risk varies widely among nations, metabolic disorders are found in in approximately $40 \%$ to $50 \%$ of children with urolithiasis[2]. The disease is endemic in Pakistan, Turkey, and Saudi Arabia, as well as in some South Asian and African countries. Hot climate, poverty, paucity of clean water, and malnourishment are contributing factors[3].

Urinary stones are typically classified by their location or by their chemical composition. Pediatric urolithiasis is a multifactorial disease, rightly considered by many as a symptom of underlying abnormality, either metabolic or anatomical, having poorly understood etiopathogenesis[4]. Supersaturation-crystallization is the most widely accepted theory. Most patients present with non-specific symptoms. Late presentation is a norm leading to significant

\section{Key Words}

Child, calcium oxalate, crystallization, hypercalciuria, lithiasis, magnesium, uric acid, urinalysis

\section{Competing Interests}

None declared

\section{Article Information}

Received on July 22, 2020

Accepted on September 28, 2020

Soc Int Urol J. 2021;2(1):18-24 
delay in the diagnosis. Ultrasonography is the preferred preliminary investigation, as it is non-invasive, easily available, and repeatable[5]. Thorough metabolic evaluation of all children who have renal stones is the linchpin if morbidity and long-term renal complications are to be prevented. Moreover, stone disease carries a high probability of recurrence among children, necessitating early identification of those at risk, prophylaxis, and lifestyle modifications. The 24-hour urine screening test is the most important tool in the diagnostic workup of children presenting with urinary lithiasis[6].

In adults, treatment options include watchful waiting, extracorporeal shock wave lithotripsy, ureterorenoscopy, percutaneous nephrolithotomy, and open removal. In children, however, extracorporeal shock wave lithotripsy and minimal invasive procedures utilizing smaller diameter scopes are preferred[7]. Prophylactic treatment to prevent recurrence depends upon identification of metabolic abnormalities among those at risk.

Studies conducted worldwide have found a very high incidence of metabolic abnormalities when children presenting with nephrolithiasis were subjected to metabolic screening[8]. In recent years, several studies have studied metabolic evaluation of stone formers, but most deal with adult populations compounded by presence of limited local data having small sample size and absence of 24-hour urinary metabolic screening[9]. In this context, the current study aims to assess the frequency of metabolic abnormalities among local children presenting with urolithiasis. This is intended to help clinicians design management protocols that incorporate urine metabolic screening as an integral part, with a view to preventing stone recurrence.

\section{Methods}

This descriptive cross-sectional study was conducted at the Department of Urology and Renal Transplantation, AFIU Rawalpindi Pakistan, a quaternary care state-ofthe-art facility, from 30 January 2017 to 1 February 2020. Approval was provided by the hospital's ethical review board (Certificate \# Uro-Adm-Trg-1/IRB/2017/106), an independently organized body adhering to the guidelines of the Declaration of Helsinki, the WHO, and the International Council on Harmonization and Good Practice (ICH-GCP). Over a 3-year period, a non-probability consecutive sampling technique was used to enroll 1355 patients who met the inclusion criteria (children of both sexes, aged 4 to 14 years, with a confirmed diagnosis of renal stones), while those who had PUJO, urinary tract infections, PUV, vesicoureteral reflux, inadequate 24-hour urine samples, and CRF were excluded. Written informed consent was obtained from the patients and their guardians as deemed appropriate.
All urine samples were obtained from the patients, without dietary restrictions, once lithiasis and/or associated UTI had been treated. Clean plastic bottles having $10 \mathrm{~mL}$ of $6 \mathrm{M}$ hydrochloric acid as preservative were used to collect 24-hour urine samples, and additional samples were collected without preservative to measure uric acid. Collection adequacy was verified by urine creatinine excretion rate. Urinary calcium, magnesium, citrate, oxalate, and uric acid were determined by a calorimetric method with ADVIA 1800 Clinical Chemistry System (Siemens Medical Solutions, Malvern, US), while $\mathrm{pH}$ was measured by the Mission Expert urinalysis reagent strips (Acon Laboratories Inc., San Diego, US). Presence or absence of metabolic abnormalities ie, hypercalciuria, hyperoxaluria, hypocitraturia, hyperuricosuria and hypomagnesuria (as per operational definition), as well as demographic details (age, sex, residence, educational status, BMI, urine volume, duration of symptoms, clinical presentation, family history of urolithiasis, stone laterality, and stone recurrence) were recorded on a specially designed proforma. Stone recurrence was defined as symptomatic stone recurrence diagnosed on ultrasound or CT scan a minimum 30 days after complete clearance of stones. The following values were used to define abnormalities on 24-hour urine: creatinine (12 to $30 \mathrm{mg} /$ $\mathrm{kg})$, hypocitraturia $\left(<365 \mathrm{mg} / 1.73 \mathrm{~m}^{2}\right.$ for boys and $<$ $310 \mathrm{mg} / 1.73 \mathrm{~m}^{2}$ for girls), hypercalciuria $(>4 \mathrm{mg} / \mathrm{kg})$, hyperoxaluria $\left(>45 \mathrm{mg} / 1.73 \mathrm{~m}^{2}\right)$, hypomagnesuria $(<$ $1.2 \mathrm{mg} / \mathrm{kg})$, hyperuricosuria $(>9.3 \mathrm{mg} / \mathrm{kg})$ and low urine volume $(<1 \mathrm{~mL} / \mathrm{kg} / \mathrm{hr} \times 24 \mathrm{hrs})$.

Statistical analysis was done using IBM SPSS Statistics for Windows, Version 24.0. (Armonk, NY: IBM Corp). Descriptive statistics were used to calculate means \pm standard deviation for quantitative variables, while frequencies with percentage were calculated for qualitative variables, significance being determined by Student $t$ test and chi-square test, respectively. Effect modifiers like age, sex, duration of disease, stone laterality, and recurrence were controlled by stratification. Post-stratification chi-square was applied to determine the effect on metabolic abnormalities. $P \leq 0.05$ was considered significant.

\section{Results}

The study analysis included 1355 patients $(75.7 \%$ of total 1789 reported; $434(24.3 \%)$ excluded) with mean age $8.54 \pm 2.47$ years, and male to female ratio 1.25:1. Low urine volume was found in 465 (34.3\%) of the patients. Three hundred nine patients $(22.8 \%)$ were found to have metabolic abnormalities.

Mean age of presentation was significantly younger in those having metabolic abnormalities (7.8 \pm 2.3 versus $8.8 \pm 2.5 ; P<0.001$ ), and more male than female 
patients were affected with metabolic derangements (1.6:1 versus $1.2: 1 ; P<0.01$ ). Disease duration and BMI were significantly lower in patients with metabolic abnormalities $(P<0.001)$, who also exhibited frequent bilateral recurrent stones and positive family history (in all cases, the difference was statistically significant, $P<0.001$ ) (Table 1).

In the 309 patients with metabolic abnormalities, hypocitraturia $(184,59.5 \%)$ was the most common derangement, followed by hypocalciuria and hypomagnesuria (Table 2). When broken down by each type of metabolic abnormality individually, there was no statistically significant difference between subgroups of children stratified by sex, disease duration ( \pm 6 months), stone laterality (right, left, or bilateral) and presence or absence of recurrence (Table 3 ).

\section{Discussion}

Urinary lithiasis in pediatric populations is relatively rare but increasing steadily across the globe[1]. Several factors can predispose children to nephrolithiasis, notably metabolic and genitourinary abnormalities [4]. Recurrence is a hallmark of childhood stone disease, imposing considerable morbidity and cost[6]. The current study was conducted to determine the frequency of metabolic derangement among local children presenting with renal stones.

Our results show concordance with national as well as international literature, albeit with a different study population. In a study by Rizvi et al.[10], the M: $\mathrm{F}$ ratio was $2.7: 1$, the mean age was $7.1 \pm 3.8$ years, and patients and malnutrition in their patients. Metabolic evaluation was performed in 1892 children, revealing hypovolemia, hypocitraturia, and hyperoxaluria. Our findings were similar with respect to age, nutritional status, and low urine volume, and hypocitraturia being the most common abnormality, but not with respect to sex distribution. However, in keeping with our findings, other studies have reported a male preponderance in children with metabolic abnormalities[3,11]. Children in our study who had metabolic abnormalities were younger, had earlier presentation, presented more frequently with bilateral stones, and were more likely to have positive family history.

There is wide variation in the reported frequency of metabolic abnormality (33\% to $93 \%$ of children with renal stones), depending upon geographical region of the study. Issler et al.[8] in their review carried in the UK found a frequency of $34 \%$, similar to our findings, while studies by Elmecai et al. in Turkey[12] and Gajengi et al. in India[13] reported $83.2 \%$ and $64 \%$, respectively. Similarly, Bilge et al.[14] in their study analyzed children aged $16.8 \pm 14.9$ months and found metabolic abnormalities in $17.8 \%$ of cases, hypercalciuria being the most common (88.9\%). Barata et al.[15] in a retrospective analysis of children with nephrolithiasis in Brazil reported a $13.6 \%$ frequency of metabolic abnormality. The most frequent disorders found were hypercalciuria, hyperuricosuria, and hypocitraturia. Frequency was $22.8 \%$ in this study. The higher frequency may be due to a hot, humid climate, and, in keeping with the international literature, bilateral and recurrent stones were associated with positive family history. However, in contrast to our results, obesity rather than malnutrition was associated with metabolic abnormality as also indicated by Bandari et al.[16].

Ethnic and geographic differences may account for the variations in the reported prevalence of abnormalities in children with metabolic disorder. Elmecai et al.[12] studied 143 preschool children and found hyperuricosuria and hypocitraturia to be most frequent disorders $(24.5 \%$ and $23.8 \%$ respectively). They also found that $16.8 \%$ of patients had multiple metabolic abnormalities. In a study of 100 Iranian children with urolithiasis, Sadeghi et al.[17] reported hypocitraturia (64\%) to be most common abnormality followed by hypercalciuria (56\%), while Velásquez-Forero et al.[18] found hypocitraturia in $70 \%$, hypomagnesuria in $42 \%$, and hypercalciuria in $37 \%$ of Mexican children evaluated. Van Dervoort et al.[19] similarly observed hypocitraturia to be the most commonly identified metabolic abnormality in a US population, present in $52 \%$ of the children, but Rellum et al. found hypercalciuria to be most common in a Dutch cohort, present in 47\%[20]. Our results revealed hypocitraturia in $59.5 \%$ children, hypocalciuria in $44 \%$, and hypomagnesuria in $40.8 \%$, while $14.6 \%$ had hyperuricosuria, and hyperoxaluria was present in $9.4 \%$, which is consistent with the findings of previous reports $[6,21]$. However, in contrast to our findings, Copelovitch et al.[22] reported hypercalciuria in 30\% to $50 \%$ of the cases, and Nasseri et al.[23], and Amancio et al.[24] reported hyperuricosuria as a frequent metabolic change. Similarly, Isler et al.[8] reported hypercalciuria in $52 \%$, hyperoxaluria in $21 \%$, and cystinuria in $22 \%$, while $27 \%$ also had bilateral stones. Children with metabolic abnormalities in the current study had bilateral stones in $19.4 \%$ of cases compared to $2.6 \%$ in children without metabolic abnormalities $(P<0.001)$. A statistically significant relation was revealed among bilateral, recurrent stones, and family history in our study, underscoring the importance of metabolic assessment in children, as early identification allows targeted treatment which mitigates recurrence among those with longer life expectancy. As ours is a referral institute with a wide catchment area, our cohort of the represent all socioeconomic strata of the society, thus allowing generalization of the results. 


\section{TABLE 1.}

Demographic features of children presenting with renal stones ( $n=1355)$

\begin{tabular}{|c|c|c|c|}
\hline Demographic Variable & $\begin{array}{l}\text { Patients Without Metabolic } \\
\text { Abnormalities }(n=1046)\end{array}$ & $\begin{array}{l}\text { Patients with Metabolic } \\
\text { Abnormalities (n=309) }\end{array}$ & PValue \\
\hline Age of the patient $(m e a n \pm S D)$ & $8.8 \pm 2.5$ & $7.8 \pm 2.3$ & $<0.001$ \\
\hline Gender distribution (M:F) & $563: 483$ & 191:118 & 0.013 \\
\hline BMI $\left(\mathbf{k g} / \mathrm{m}^{2}\right)$ & $16.3 \pm 1.3$ & $15.6 \pm 1.5$ & $<0.001$ \\
\hline Disease duration (months) & $8.4 \pm 1.5$ & $7.7 \pm 1.5$ & $<0.001$ \\
\hline $\begin{array}{r}\text { Urine volume }(\mathrm{mL} / \mathrm{kg}) \quad \text { Normal } \\
\text { Low }\end{array}$ & $\begin{array}{l}686(65.6) \\
360(34.4)\end{array}$ & $\begin{array}{l}204(66.1) \\
105(33.9)\end{array}$ & 0.89 \\
\hline $\begin{array}{l}\text { Residence (n \%) } \\
\text { Urban } \\
\text { Rural }\end{array}$ & $\begin{array}{l}515(49.2) \\
531(50.8)\end{array}$ & $\begin{array}{l}143(46.3) \\
156(53.7)\end{array}$ & 0.36 \\
\hline $\begin{array}{l}\text { Educational status ( } \mathbf{n} \%) \\
\text { Not attending school } \\
\text { Attending school } \\
\text { Disconnected education }\end{array}$ & $\begin{array}{l}180(17.2) \\
670(64.1) \\
196(18.7)\end{array}$ & $\begin{array}{l}53(17.2) \\
184(59.5) \\
72(23.3)\end{array}$ & 0.19 \\
\hline $\begin{array}{l}\text { Recurrent stones (n \%) } \\
\qquad \begin{array}{r}\text { Yes } \\
\text { No }\end{array}\end{array}$ & $\begin{array}{l}114(10.9) \\
932(89.1)\end{array}$ & $\begin{array}{l}108(35) \\
201(65)\end{array}$ & $<0.001$ \\
\hline Family counselling (n \%) & $\begin{array}{l}728(69.6) \\
318(30.4)\end{array}$ & $\begin{array}{l}229(74.1) \\
80(25.9)\end{array}$ & 0.13 \\
\hline $\begin{array}{l}\text { Stone laterality (n \%) } \\
\qquad \begin{array}{r}\text { Right } \\
\text { Left } \\
\text { Bilateral }\end{array}\end{array}$ & $\begin{array}{c}490(46.8) \\
529(50.6) \\
27(2.6)\end{array}$ & $\begin{array}{l}116(37.5) \\
133(43) \\
60(19.4)\end{array}$ & $<0.001$ \\
\hline $\begin{array}{l}\text { Family history urolithiasis (n \%) } \\
\qquad \begin{array}{r}\text { Yes } \\
\text { No }\end{array}\end{array}$ & $\begin{array}{c}94(9) \\
952(91)\end{array}$ & $\begin{array}{l}116(37.5) \\
193(62.5)\end{array}$ & $<0.001$ \\
\hline 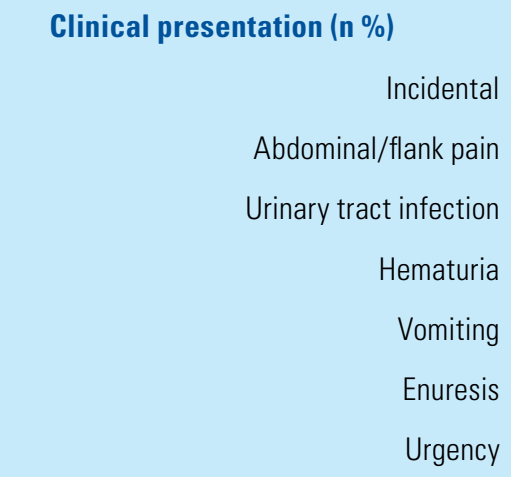 & $\begin{array}{c}88(8.4) \\
260(24.9) \\
434(41.5) \\
154(14.7) \\
52(5) \\
37(3.5) \\
21(2)\end{array}$ & $\begin{array}{c}25(8.1) \\
73(23.6) \\
130(42.1) \\
49(15.9) \\
15(4.9) \\
08(2.6) \\
09(2.9)\end{array}$ & 0.93 \\
\hline
\end{tabular}


TABLE 2.

Frequency of various metabolic abnormalities among children diagnosed with metabolic abnormalities

\begin{tabular}{|c|c|c|}
\hline \multirow{2}{*}{ Metabolic Disorder } & \multicolumn{2}{|c|}{ Frequency (n \%) } \\
\hline & Yes & No \\
\hline Hypocitraturia & $184(59.5)$ & $125(40.5)$ \\
\hline Hypercalciuria & $136(44)$ & $173(56)$ \\
\hline Hypomagnesuria & $126(40.8)$ & 183(59.2) \\
\hline Hyperuricosuria & $45(14.6)$ & $264(85.4)$ \\
\hline Hyperoxaluria & $29(9.4)$ & $280(90.6)$ \\
\hline
\end{tabular}

More recent studies conducted in China[25] and the $\mathrm{UK}[26]$ found hypocitraturia and cystinuria to be the most common abnormalities. Cystinuria has a reported frequency of $2 \%$ to $8 \%$. Our study did not report this abnormality as our institution does not have the capacity to test for it. Different dietary habits and hereditary factors might influence differences in urine chemistry results explaining variegated pattern of frequencies world over. Stone analysis was performed in various studies across the globe finding calcium oxalate and phosphate among $77 \%$ to $86 \%$ of the patients $[9,20]$, however such details were not reported in the studied patients so the type of stone cannot be commented upon.

No significant difference was found in the frequency of abnormal urinary metabolic parameters between boys and girls $(P>0.05)$, which is consistent with results of Elmaci et al.[12]. Similarly, we did not find any difference in metabolic abnormalities with respect to age, laterality, and recurrence. Our data showed significantly lower

\section{TABLE 3.}

Data stratification with respect to disease duration, stone laterality and recurrence in children having metabolic abnormalities $(n=309)$
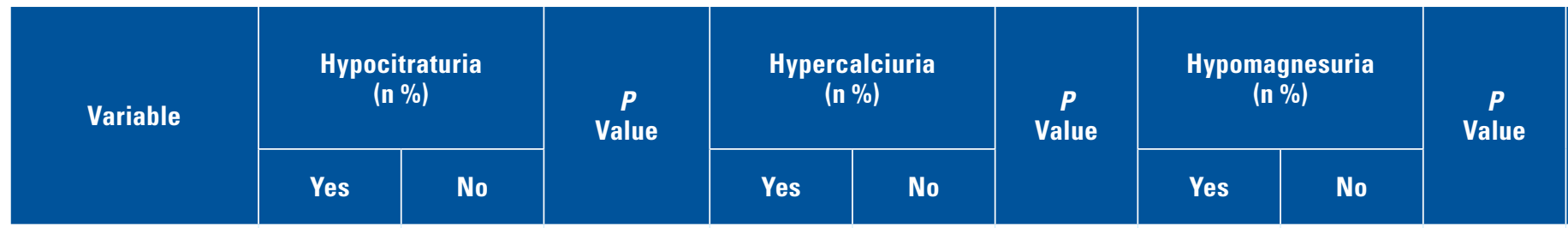

Disease duration

\begin{tabular}{|c|c|}
\hline$<06$ Months & $37(12)$ \\
\hline 06 Months & 147(48) \\
\hline
\end{tabular}

0.79

28(9)

34(11)

0.79

27(9)

35(11)

0.25

0.84

108(35)

139(45)

0.91

99(32)

148(50)

0.82

Stone laterality

\begin{tabular}{r|c|c|c|} 
Right & $71(23)$ & $45(15)$ & $\mathbf{0 . 1 9}$ \\
\hline Left & $80(26)$ & $53(17)$ & $\mathbf{0 . 1 6}$ \\
\hline Bilateral & $33(11)$ & $27(9)$ & $\mathbf{0 . 4 5}$ \\
\hline
\end{tabular}

0.19
0.16
0.45

\begin{tabular}{|l|l|}
\hline $60(19)$ & $56(18)$ \\
\hline $46(14)$ & $87(28)$ \\
\hline $30(10)$ & $30(10)$
\end{tabular}

0.95

41(13)

75(24)

0.44

0.71

62(20)

71(23)

0.35

\section{Stone recurrence}

\begin{tabular}{|l|l|r|} 
Yes & $67(22)$ & $41(13)$ \\
\hline No & $84(27)$ & $117(38)$ \\
\hline
\end{tabular}

0.32
0.52

$54(17)$
$82(26)$

30(10)

0.77

23(7)

$37(12)$

0.44 
7. Grivas N, Thomas K, Drake T, Donaldson J, Neisius A, Petřík A, et al. Imaging modalities and treatment of paediatric upper tract urolithiasis: a systematic review and update on behalf of the EAU urolithiasis guidelines panel. J Pediat Urol. 2020 Jul 4. DOI: 10.1016/j.jpurol.2020.07.003

8. Issler N, Dufek S, Kleta R, Bockenhauer D, Smeulders N, Hoff WV. Epidemiology of paediatric renal stone disease: a 22-year single center experience in the UK. BMC Nephrol. 2017; 18:136. DOI:10.1186/s12882-017-0505-X.

9. Imran K, Zafar MN, Fatima N, Ozair U, Sultan S, Rizvi SA. Chemical composition of stones in paediatric urolithiasis. J Ayub Med Coll Abbottabad. 2017: 29:630-4.

10. Rizvi SAH, Sultan S, Zafar MN, Ahmed B, Faiq SM, Hossain KZ, et al. Evaluation of children with urolithiasis. Indian J Urol. 2007; 23(4): 420-7. DOI:10.4103/0970-1591.36717.

11. Sas DJ, Becton LJ, Tutman J, Lindsay LA, Wahlquist AH. Clinical, demographic, and laboratory characteristics of children with nephrolithiasis. Urolithiasis. 2016;44(3):241-246. D0I:10.1007/ s00240-015-0827-8.

12. Elmaci AM, Ece A, Akin F. Clinical characteristics and metabolic abnormalities in preschool-age children with urolithiasis in southeast Anatolia. J Pediatr Urol. 2013; 10:495-499.

13. Gajengi AKR, Wagaskar VG, Tanwawar HV, Mhaske S, Patwawardhan SK. Metabolic evaluation in paediatric urolithiasis: a 4-year open prospective study. J Clin Diagn Res. 2016; 10(2):04-06.

14. Bilge I, Yilmaz A, Kayiran SM, Emre S, Kadioglu A, Yekeler E, Sucu A, Sirin A. Clinical importance of renal calyceal microlithiasis in children. Pediatr Int. 2013;55(6):731-6.

15. Barata CB, Valete COS. Clinical-epidemiological profile of 106 pediatric patients with urolithiasis in Rio De Janeiro, Brazil. Rev Paul Pediatr. 2018; 36(3):261-267. DOI:10.1590/1984-0462/;2018;36;3;00009.

16. Bandari J, Dangle PP, Lyon TD, Lee A, Schneck FX, Cannon GM, et al. 24-hour urinary parameters in overweight or obese children with urolithiasis. J Urol. 2016; 196:526-30.

17. Sadeghi S, Fazeli F, Zarifi E. Clinical characteristics and metabolic abnormalities in pediatric urolithiasis in South East Iran (Zahedan). J Ped Nephrol. 2015;3(4):149-54.

18. Velásquez-Forero F, Esparza E, Salas A, Medeiros M, Toussaint G, Llach F. Risk factors evaluation for urolithiasis among children. Bol Med Hosp Infant Mex. 2016;73:228-36. D0I:10.1016/j. bmhimx.2016.05.006.
19. VanDervoort K, Wiesen J, Frank R, et al. Urolithiasis in pediatric patients: a single center study of incidence, clinical presentation and outcome. J Urol. 2007; 177:2300-5.

20. Rellum DM, Feitz WF, van Herwaarden AE, Schreuder MF. Pediatric urolithiasis in a non-endemic country: A single center experience from The Netherlands. J Pediatr Urol. 2014;10:155-161.

21. Jobs K, Rakowska M, Paturej A. Urolithiasis in the pediatric population-current opinion on epidemiology, pathophysiology, diagnostic evaluation and treatment. Dev Period Med. 2018;22(2):201-208.

22. Copelovitch L. Urolithiasis in children-medical approach. Paediatr Clin North Am. 2012:59(4); 881-96. D0I:10.1016/j.pcl.2012.05.009

23. Naseri M, Varasteh AR, Alamdaran SA. Metabolic factors associated with urinary calculi in children. Iran J Kidney Dis. 2010; 4:32-8.

24. Amancio L, Fedrizzi M, Bresolin NL, Penido MG. Pediatric urolithiasis: experience at a tertiary care pediatric hospital. J Bras Nefrol. 2016; 38:90-8.

25. Yang D, Tiselius $H$, Lan $C$, Chen $D$, Chen $K$, Ou L, et al. Metabolic disturbances in Chinese children with urolithiasis: a single center report. Urolithiasis. 2017;45(3):285-290. D0I: 10.1007/ s00240-016-0910-9.

26. Coward RJ, Peters CJ, Duffy PG, et al. Epidemiology of paediatric renal stone disease in the UK. Arch Dis Child. 2003;88:962-965.

27. Ferraro PM, Arrabal-Polo MÁ, Capasso G, Croppi E, Cupisti A, Ernandez T, et al. A preliminary survey of practice patterns across several European kidney stone centers and a call for action in developing shared practice. Urolithiasis. 2019 Jun; 47(3):219-224. DOI: 10.1007/s00240-019-01119-z. Epub 2019 Mar 8.

28. Gouru VR, Pogula VR, Vaddi SP, Manne V, Byram R, Kadiyala LS. Metabolic evaluation of children with urolithiasis. Urol Ann. 2018; 10(1):94-99. D0I:10.4103/UA.UA_98_17.

29. Lekhlifia ZE, Laziri F, Samihb M, Hidac M, Bouabdillahc Y, Souilmi FZ. Epidemiological characteristics of childhood urolithiasis in Morocco. Afr J Urol. 2016; 22(2):92-5. D0I:10.1016/j.afju.2016.01.009. 